\title{
Coracoid impingement syndrome: a literature review
}

\author{
T. Okoro $\cdot$ V. R. M. Reddy $\cdot$ Ashvin Pimpelnarkar
}

Published online: 27 January 2009

(C) The Author(s) 2009. This article is published with open access at Springerlink.com

\begin{abstract}
Coracoid impingement syndrome is a less common cause of shoulder pain. Symptoms are presumed to occur when the subscapularis tendon impinges between the coracoid and lesser tuberosity of the humerus. Coracoid impingement should be included in the differential diagnosis when evaluating a patient with activity-related anterior shoulder pain. It is not thought to be as common as subacromial impingement, and the possibility of the coexistence of the two conditions must be taken into consideration before treatment of either as an isolated process. If nonoperative treatment fails to relieve symptoms, surgical decompression can be offered as an option.
\end{abstract}

Keywords Coracoid impingement .

Anterior shoulder pain

\section{Introduction}

The mechanical impingement on the rotator cuff by the overlying acromial arch was postulated early in 1909 [1]. The same article also considered the possibility of rotator cuff impingement by its anteromedial portion, that is, the

T. Okoro $(\bowtie)$

University Hospitals Leicester NHS Trust, Leicester General

Hospital, Gwendolen Road, Leicester LE5 4PW, UK

e-mail: tosanwumi@hotmail.com

\section{R. M. Reddy}

University Hospitals Leicester NHS Trust, Glenfield Hospital, Leicester LE3 9QP, UK

\section{A. Pimpelnarkar}

Heart of England NHS Foundation Trust, Good Hope Hospital, Sutton Coldfield, Birmingham B75 7RR, UK coracoid process. Coracoid impingement was also described in 1937 [2] and in 1941 [3].

The coracoacromial interval includes the acromion, the coracoacromial ligament, and the tip of the coracoid process (Fig. 1) [4]. It is the variation in the height and length of the coracoid process in most cases that is responsible for altering the size and shape of the space between the coracoacromial arch and the rotator cuff [5]. A recent cadaveric study also suggests that the problem is functional with anterior instability leading to a narrowing of the coracohumeral distance [6].

There are no reports in the published literature of the incidence or prevalence of this condition.

Coracoid impingement syndrome is a less common cause of shoulder pain. Symptoms are presumed to occur when the subscapularis tendon impinges between the coracoid and lesser tuberosity of the humerus [7]. This causes tendinosis and pain in the soft tissues. The causes are classified as idiopathic, traumatic, or iatrogenic, (Table 1) [8-10].

\section{Diagnosis}

The syndrome is most common after a history of chronic overuse with multiple episodes of microtrauma, especially when the shoulder is persistently in a forward-elevated, adducted and internally rotated position [8]. Patients with this syndrome typically present with a history of dull pain in the anterior aspect of the shoulder that is exacerbated by activities performed when the shoulder is in a forward flexed, adducted and internally rotated position [11].

The diagnosis of coracoid impingement has not been extensively studied, and it remains a diagnosis of exclusion based on the findings of the physical examination, the results of injections, and radiographic features [10]. It is 


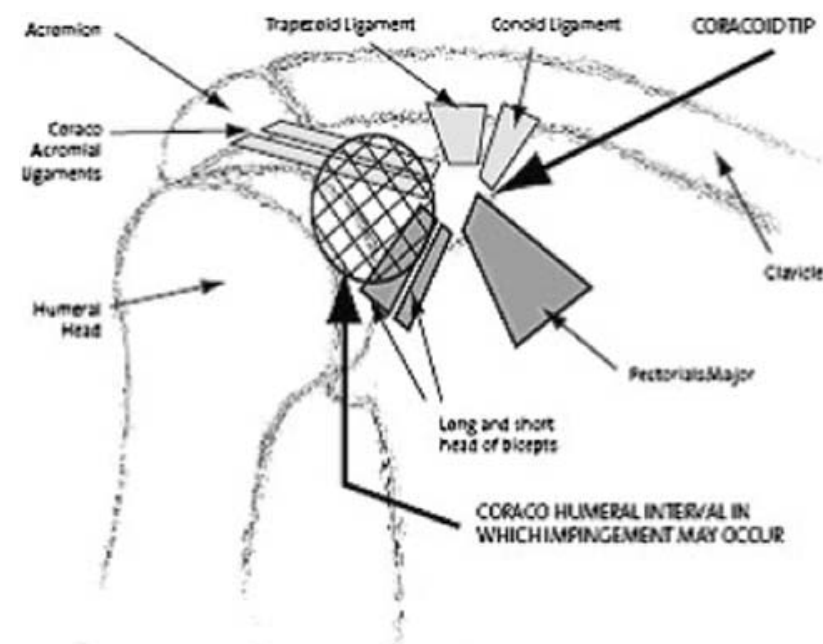

Fig. 1 Anterior view of shoulder joint demonstrating coracoid process and surrounding structures [4]

Table 1 Causes of coracoid impingement syndrome [8-10]

\begin{tabular}{|c|c|}
\hline Idiopathic & Malpositioned coracoid tip \\
\hline & Calcification of the coracoid tip, subscapularis tendon \\
\hline Traumatic & Humeral head and neck fracture \\
\hline & Malunion of previous coracoid or glenoid fracture \\
\hline & Displaced fractures of scapular neck \\
\hline & Posterior sternoclavicular dislocation \\
\hline Iatrogenic & $\begin{array}{l}\text { Previous anterior shoulder surgery (Bristow/Trillat } \\
\text { procedure) }\end{array}$ \\
\hline & Posterior glenoid osteotomy \\
\hline & Acromionectomy \\
\hline
\end{tabular}

also an important entity to be aware of as it is a cause of persistent postoperative shoulder pain after rotator cuff repair [12].

Physical examination follows the orthopaedic edict of 'Look, Feel, and Move'. It is important to look for previous scars and any obvious deformity in the shoulder area. Palpation often elicits tenderness of the soft tissues around the coracoid process and between the coracoid process and the lesser tuberosity [8]. The coracoid impingement test is performed in a manner similar to that used to perform the Kennedy-Hawkins impingement sign, except that the patient's shoulder is placed in a position of cross arm adduction, forward elevation, and internal rotation to bring the lesser tuberosity in contact with the coracoid [13]. Pain is elicited more consistently in the midrange of forward elevation than in the full elevation that is used to detect subacromial impingement [10]. The coracoid impingement test is passive on the part of the patient, and this is used to differentiate it from the superior labrum test [14] which requires the patient to resist downward pressure on the arm.
Another method that is used to evaluate whether a patient has coracoid impingement is to inject lignocaine into the subcoracoid region [13]. Although it has been suggested that relief of pain with this injection can help to establish the diagnosis, this test has not been studied to determine either its validity or its accuracy [15]. The proximity of multiple structures in the subcoracoid region, including the joint itself, makes the accuracy of these injections questionable.

Radiological investigations include 'X-rays' of the shoulder, in particular an AP view and an axillary view perpendicular to the plane of the scapula (Fig. 2). These can detect anatomical aberrations that may be contributing

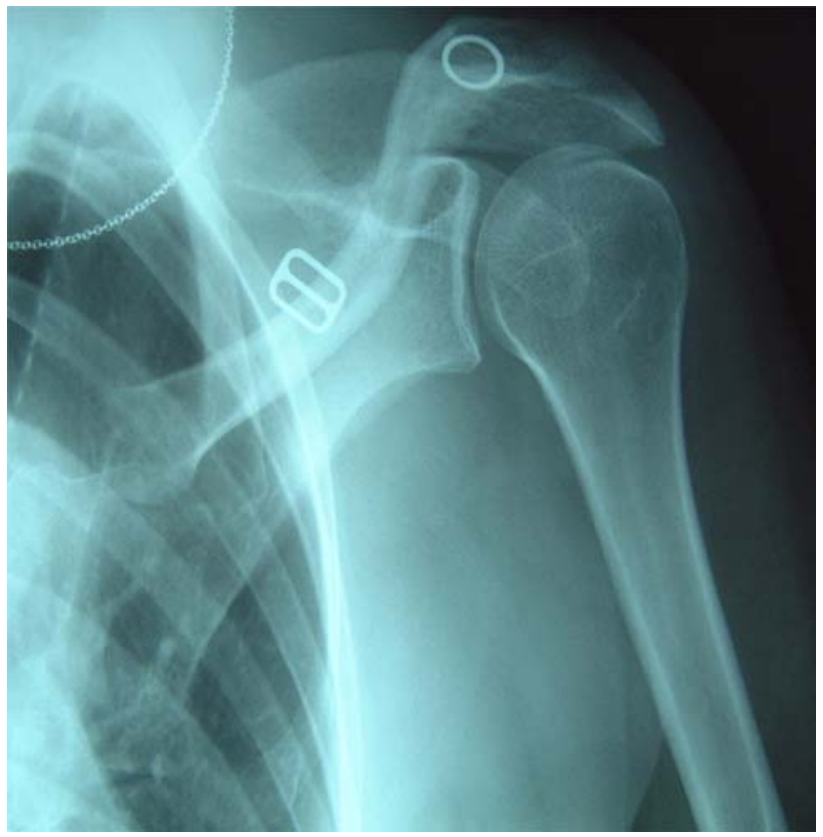

Fig. 2 Plain X-Rays demonstrating a laterally projecting coracoid causing impingement

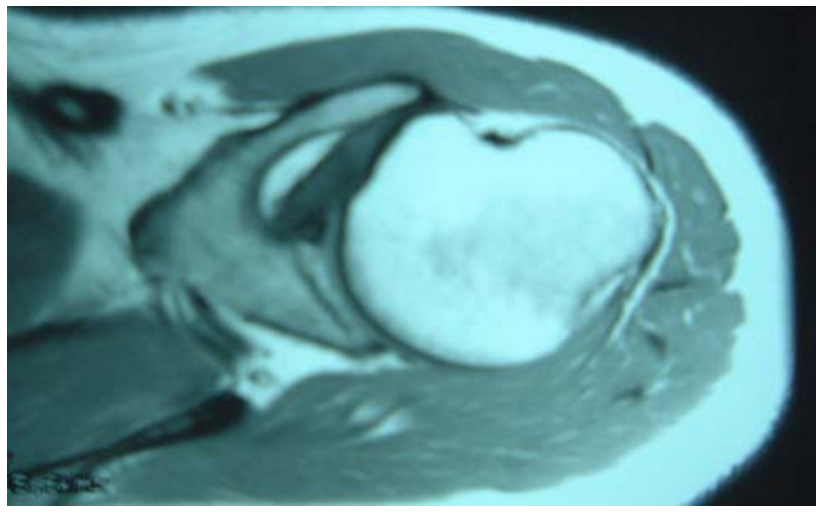

Fig. 3 MRI Scan demonstrating coracohumeral interval in the same patient as in Fig. 2: the distance between the coracoid tip and the closest portion of the proximal part of the humerus 
to the impingement. MRI and CT scans are useful for further delineating coracoid or subcoracoid anatomy. An axial CT view is used to assess the coracoid index, which is a measurement of the lateral projection of the coracoid process beyond a line tangential to the articular surface of the glenoid [13]. This is a linear measurement in millimetres. The average index in 67 normal shoulders was $8.2 \mathrm{~mm}$ [13]. It has also been suggested that there should be a minimum distance of $6.8 \mathrm{~mm}$ between the coracoid tip and the closest portion of the proximal part of the humerus
[11]. The latter distance is measured best on an axial MRI scan with the humerus in maximal internal rotation.

In asymptomatic patients, the average coracohumeral interval (Fig. 3) measures $11 \mathrm{~mm}$ in maximal internal rotation, with none measuring $<4 \mathrm{~mm}$ [16]. Symptomatic patients had an average interval of $5.5 \mathrm{~mm}$ in maximal internal rotation. This study by Friedman et al. [16] also noted that there is no redundancy of the subscapularis tendon in asymptomatic patients with the arm in full internal rotation. The sensitivity of this particular position
Fig. 4 Algorithm for the diagnosis and management of coracoid impingement $[7,23$, 24]

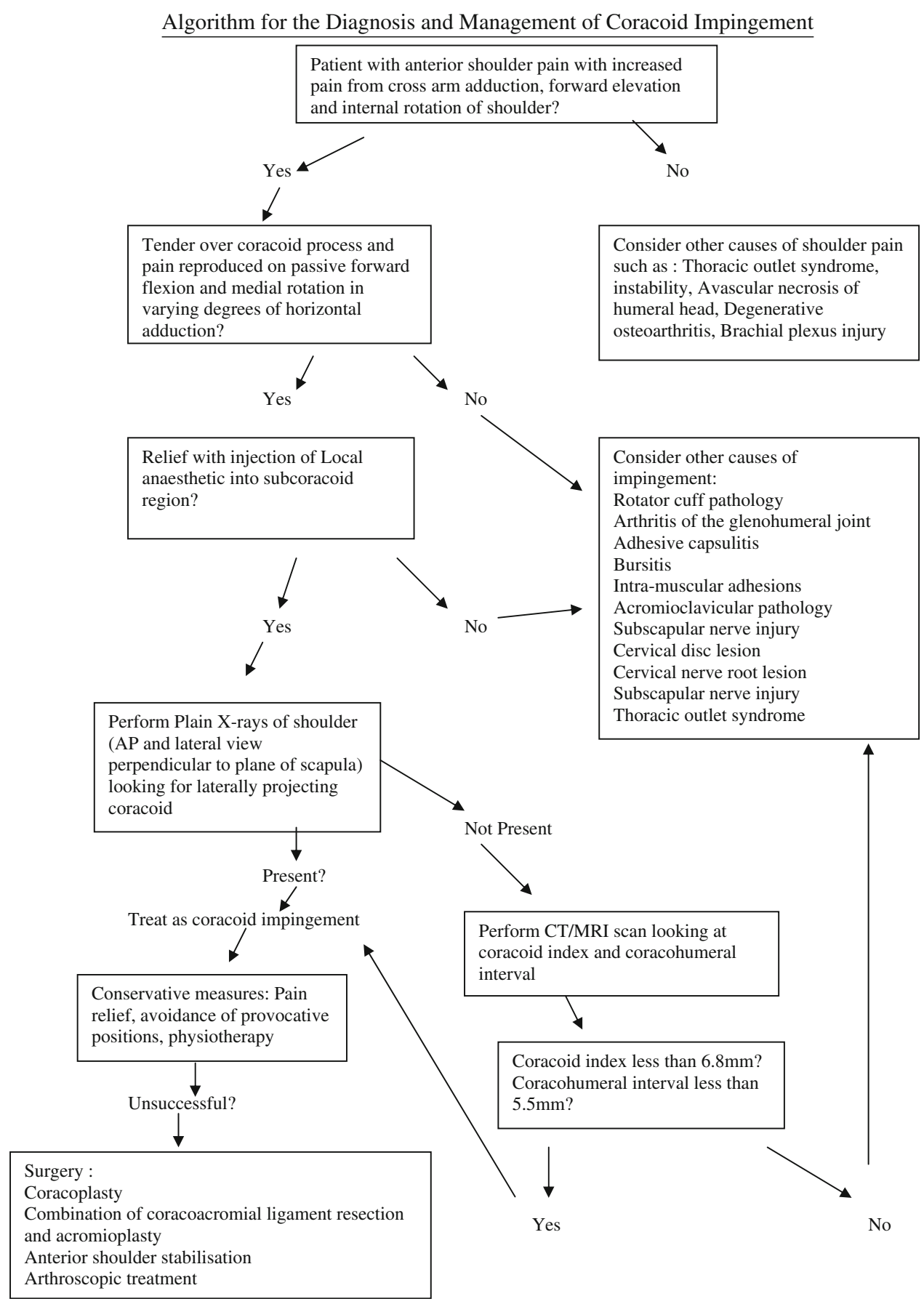


in detecting coracoid impingement on MRI is only 5.3\% with specificity of $97.6 \%$ [17]. This suggests that subcoracoid impingement appears to be largely a clinical diagnosis that may be supported or suggested, but not established, by MRI [17]. Patients with subcoracoid impingement also demonstrate increased soft tissue in the subcoracoid space because of redundancy or folding of the subscapularis tendon and capsular tissues when the shoulder is in this provocative position of maximum internal rotation.

A chevron-shaped $\left(^{\wedge}\right)$ supraspinatus outlet also appears to be synonymous with a diagnosis of subcoracoid impingement. All the 12 cases of primary coracoid impingement syndrome treated surgically had chevronshaped outlets similar to the shape used as US army rank insignia [18]. All the coracoid tips in these instances were inferior to the superior glenoid tubercle and the outlets were circumflex-shaped compared with normal (this compares to a $23 \%$ incidence of similar circumflex shaped outlets in a series of 150 cadaveric scapulae with a history of subacromial impingement) [19].

A final way to make the diagnosis of coracoid impingement is direct arthroscopic observation of the contact [20]. In this case series of patients with a partial rupture of the subscapularis tendon, contact was noted with the subscapularis tendon impinging between the coracoid and lesser tuberosity with the arm in a position simulating that used to elicit the coracoid impingement sign. The fact that the subscapularis tendon was torn in this instance made the observation of the contact more likely.

\section{Management}

The first line of treatment for coracoid impingement should be a program of activity modification, with avoidance of the provocative positions of forward flexion and medial rotation, and physical therapy to strengthen rotator cuff muscles and scapular stabilizer musculature [8, 10]. Figure 4 shows an algorithm that can be used to approach this scenario.

Surgical decompression of the subcoracoid space may be undertaken if the above conservative measures fail. The options include open or arthroscopic coracoplasty, a combination of coracoacromial ligament resection and acromioplasty, or anterior shoulder stabilization.

Open book coracoplasty $[13,18]$ is performed with the patient under general anaesthetic and in the beach chair position. The shoulder is examined for laxity and a diagnostic arthroscopy is performed to rule out other lesions. The coracoid is approached via a $6 \mathrm{~cm}$ anterior incision in the delto-pectoral groove. The musculocutaneous nerve is palpated for as well as the tip and base of the coracoid. The

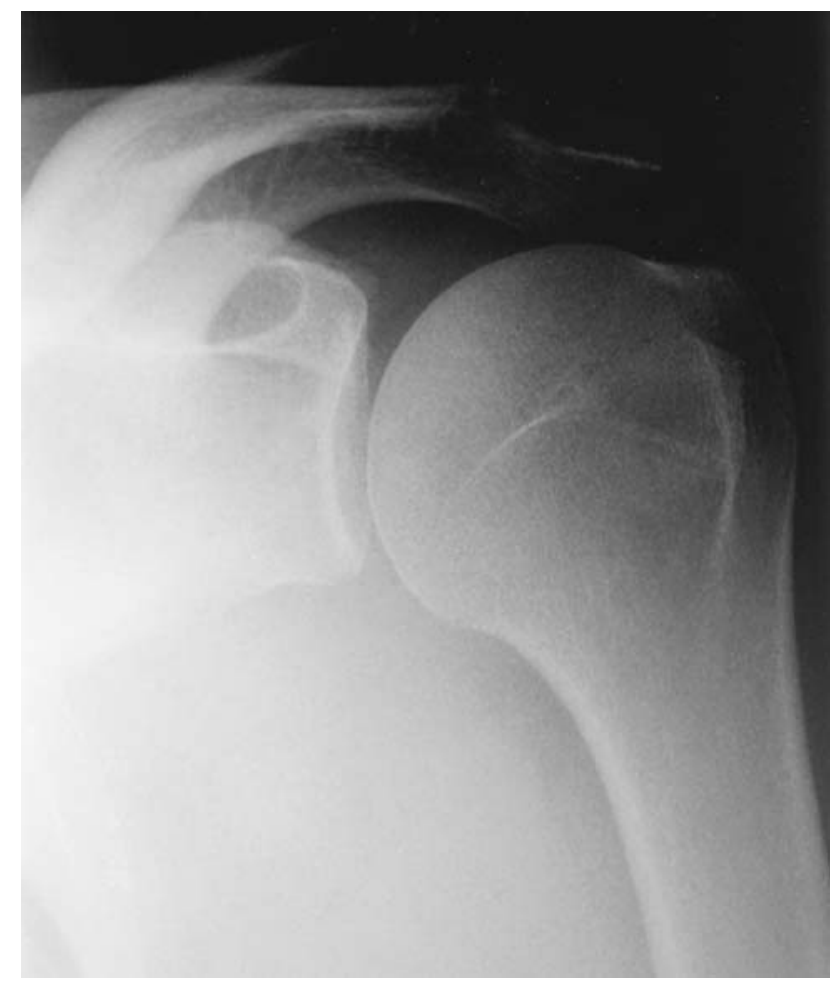

Fig. 5 Post-operative X-Ray showing the amount of coracoid resected after coracoplasty

conjoined tendon is divided for $2 \mathrm{~cm}$ and the incision continues into the coracohumeral ligament for $2 \mathrm{~cm}$. A subperiosteal dissection of the soft tissue from the lateral coracoid only is performed. After removal of the lateral portion of the coracoid process, the sharp edges of the bone are rounded and the conjoined tendon is repaired side to side to medially displace the soft tissue.

A combination of resection of the coracoacromial ligament, acromioplasty, and coracoid resection is suggested by Gerber et al. 1985 [10] because of their belief that isolated coracoid impingement is rare. Some cases of coracoid impingement caused by anterior glenohumeral instability are best treated by anterior shoulder stabilisation [21].

Arthroscopic treatment of coracoid impingement is described in a case series of four patients [22]. An advantage of the arthroscopic approach is the avoidance of conjoined tendon detachment. In addition, this technique is less invasive and requires less surgical dissection. Figure 5 illustrates the post-operative film obtained after coracoid resection.

\section{Conclusion}

Coracoid impingement should be included in the differential diagnosis when evaluating a patient with activity- 
related anterior shoulder pain. It is not thought to be as common as subacromial impingement, and the possibility of the coexistence of the two conditions must be taken into consideration before treatment of either as an isolated process. If nonoperative treatment fails to relieve symptoms, surgical decompression can be offered as an option.

Open Access This article is distributed under the terms of the Creative Commons Attribution Noncommercial License which permits any noncommercial use, distribution, and reproduction in any medium, provided the original author(s) and source are credited.

\section{References}

1. Goldthwait JE. An anatomic and mechanical study of the shoulder joint, explaining many of the cases of painful shoulder, many of the recurrent dislocations, and many of the cases of brachial neuritis. Am J Orthop Surg. 1909;6:579-606.

2. Meyer AW. Chronic Functional Lesions of shoulder. Arch Surg. 1937;35:646-74.

3. Bennett GE. Shoulder and elbow lesions of the professional baseball pitcher. JAMA. 1941;11:510-4.

4. Roche SJ, Kennedy MT, Butt AJ, Kaar K. Coracoid impingement syndrome: A treatable cause of anterior shoulder pain. Ir J Med Sci Jul-Sep. 2006;175(3):57-61.

5. Renoux S, Manet J, Pupin P, Collin M, et al. Preliminary note on biometric data relating to the human coracoacromial arch. Surg Radiol Anat. 1986;8:189-95.

6. Radas CB, Pieper HG. The coracoid impingement of the subscapularis tendon: a cadaver study. J Shoulder Elbow Surg. 2004; 13(2):154-9.

7. Ferrick MR. Coracoid impingement a case report and review of the literature. Am J Sports Med. 2000;28(1):117-9.

8. Russo R, Togo F. The subcoracoid impingement syndrome: clinical, semeiologic, and therapeutic considerations. Ital J Orthop Traumatol. 1991;17:351-8.
9. Yel M, Parham M, Burkhead WZ Jr. Old unreduced posterior sternoclavicular dislocation and coracoid impingement. Proc (Bayl Univ Med Cent). 2001;14(3):243-5.

10. Gerber C, Terrier F, Ganz R. The role of the coracoid process in the chronic impingement syndrome. J Bone Joint Surg. 1985;67B:703-8.

11. Gerber C, Terrier F, Zehnder R, et al. The subcoracoid space, an anatomic study. Clin Orthop. 1987;215:132-8.

12. Suenga N, Minami A, Kaneda K. Postoperative subcoracoid impingement syndrome in patients with rotator cuff tear. J Shoulder Elbow Surg. 2000;9:275-8.

13. Dines DM, Warren RF, Inglis AE, et al. The coracoid impingement syndrome. J Bone J Surg. 1990;72B:314-6.

14. O'Brien SJ, Pagnani MJ, Fealy S, et al. The active compression test: a new and effective test for diagnosing labral tears and acromioclavicular joint abnormality. Am J Sports Med. 1998;26:610-3.

15. McFarland EG, Selhi HS, Keyurapan E. Clinical evaluation of impingement: what to do and what works. Instr Course Lect. 2006;55:3-16.

16. Friedman RJ, Bonutti PM, Genez B. Cine magnetic resonance imaging of the subcoracoid region. Orthopaedics. 1998;21:545-8.

17. Giaroli EL, Major NM, Lemley DE, Lee J. Coracohumeral interval imaging in subcoracoid impingement syndrome on MRI. AJR Am J Roentgenol. 2006;186(1):242-6.

18. Kragh JF, Doukas-William C Jr, Basamania CJ. Primary coracoid impingement syndrome. Am J Orthop. 2004;33(5):229-32.

19. Sperner G. Role of the subacromial space on development of the impingement syndrome. Part I Unfallchirurg. 1995;98(6):301-8.

20. Lo IK, Burkhart SS. Arthroscopic coracoplasty through the rotator interval. Arthroscopy. 2003;19:667-71.

21. Patte D. The subcoracoid impingement. Clin Orthop. 1990;254: 55-9.

22. Karnaugh RD, Sperling JW, Warren RF. Arthroscopic treatment of coracoid impingement. Arthroscopy Sep. 2001;17(7):784-7.

23. Rossi F. Shoulder impingement syndromes. Eur J Radiol. 1998;27:S42-8.

24. Will LA. A conservative approach to shoulder impingement syndrome and rotator cuff disease: A case report. Clin Chiropr. $2005 ; 8: 173-8$. 